\title{
Optimized sintering and mechanical properties of Y-TZP ceramics for dental restorations by adding lithium disilicate glass ceramics
}

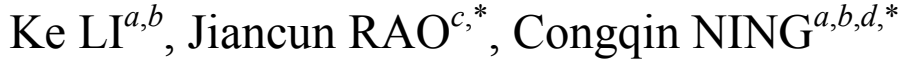 \\ ${ }^{a}$ State Key Laboratory of High Performance Ceramics and Superfine Microstructure, \\ Shanghai Institute of Ceramics, Chinese Academy of Sciences, Shanghai 200050, China \\ ${ }^{b}$ Center of Materials Science and Optoelectronics Engineering, University of \\ Chinese Academy of Sciences, Beijing 100049, China \\ 'AIM Lab, Maryland NanoCenter, University of Maryland, College Park, MD 20742, USA \\ ${ }^{d}$ The Education Ministry Key Lab of Resource Chemistry and Shanghai Key Laboratory of \\ Rare Earth Functional Materials, Shanghai Normal University, Shanghai 200234, China
}

Received: January 6, 2021; Revised: June 7, 2021; Accepted: June 11, 2021

(C) The Author(s) 2021.

\begin{abstract}
The novel dental ceramics can be fabricated at lower temperatures when sol-gel derived lithium disilicate glass ceramics (LDGC) was used as an additive for yttria stabilized tetragonal zirconia polycrystalline (Y-TZP) ceramics. The effect of LDGC on the sintering, mechanical, and translucent properties of Y-TZP ceramics was investigated in the present study. The results showed that the LDGC additive effectively improved the densification of $\mathrm{Y}-\mathrm{TZP}$ at $1100{ }^{\circ} \mathrm{C}$, which was much lower than the sintering temperature for pure Y-TZP. When sintered at $1100{ }^{\circ} \mathrm{C}$, the Y-TZP with 1 $\mathrm{wt} \%$ LDGC reached a relative density of $95.45 \%$, and prossessed a flexural strength of $482.4 \mathrm{MPa}$ and a fracture toughness of $5.94 \mathrm{MPa} \cdot \mathrm{m}^{1 / 2}$. Moreover, its translucency was also improved. While, the addition of LDGC could result in an escape of yttrium atoms from the grain lattice of zirconia, which induced the tetragonal-monoclinic transformation of zirconia and abnormal growth of monoclinic grains. The escaped yttrium atoms diffused into the intergranular glass phase. The results indicated that the novel Y-TZP-LDGC ceramics has a great potential to be used for all-ceramic restorations.
\end{abstract}

Keywords: yttria stabilized tetragonal zirconia polycrystalline (Y-TZP); lithium disilicate glass ceramics (LDGC); sintering; mechanical properties; dental restoration

\section{Introduction}

In recent years, all-ceramic restorations have attracted an increasing attention due to their unique characteristics of combining good mechanical properties, excellent

\footnotetext{
* Corresponding authors.

E-mail: J.Rao, jcrao@umd.edu;

C. Ning, cqning@shnu.edu.cn
}

biocompatibility, and aesthetic performance together [1-3]. Currently, several kinds of ceramics have been used in clinical, including lithium disilicate glass ceramics, alumina-based ceramics, feldspathic ceramics, and zirconia ceramics $[1,4,5]$. Among these materials, yttria stabilized tetragonal zirconia polycrystalline (Y-TZP) has been considered as one of the most advantageous candidates for dental restorations, such as crown, inlay, onlay, and bridge, owing to its high flexural strength (900-1200 MPa) and fracture toughness 


\section{(9-10 MPa $\left.\mathrm{m}^{1 / 2}\right)$ [6-9].}

Zirconia was initially introduced as a biomaterial for the total hip replacement in 1988 [10]. At present, zirconia plays an important role in all-ceramic restoration system. It is well-known that zirconia has much higher fracture toughness than other ceramics used in dentistry, owing to the effect of transformation-toughening phenomena associated with the martensitic transformation, i.e., tetragonal to monoclinic phase $(\mathrm{t}-\mathrm{m})[6,10]$. The volume expansion ranging from $3 \%$ to $5 \%$ of zirconia grains after this phase transition induced by localized stresses can result in the significant compressive stresses on the propagating cracks. The hindered crack propagation can effectively increase the fracture toughness of Y-TZP $[11,12]$. Y-TZP restorations are usually manufactured via a solid-state sintering at the temperature above $1500{ }^{\circ} \mathrm{C}[13,14]$. The manufacturing temperature is higher, and the product's cost is more expensive, which will inevitably limit its commercial applications [15]. The most common method to decrease the manufacturing temperature for ceramics is to use sintering additives. Actually, several researches have reported about the performance of additives on the sintering properties of Y-TZP. Those results showed that the densification of $\mathrm{Y}-\mathrm{TZP}$ could be effectively promoted due to the viscous flow of glass phase during sintering, such as $\mathrm{CaO}-\mathrm{Al}_{2} \mathrm{O}_{3}-\mathrm{SiO}_{2}(\mathrm{CAS})$ and $\mathrm{Li}_{2} \mathrm{O}-$ $\mathrm{Al}_{2} \mathrm{O}_{3}-\mathrm{SiO}_{2}$ (LAS) [13,16-20].

Lithium disilicate glass ceramics (LDGC) is polycrystalline material consisted of lithium disilicate crystalline grains and glassy phases [21]. Due to the glassy matrix and the interlocking microstructures of the needle-like lithium disilicate crystalline grains, LDGC presents a good translucency while maintaining a high strength $(>350 \mathrm{MPa})$ and a fracture toughness $\left(2.5-2.8 \mathrm{MPa} \cdot \mathrm{m}^{1 / 2}\right)$ [22]. These properties have a decisive influence on the reliability and esthetics of a restoration product. Currently, LDGC has been widely used for dental restorations, including inlays, crowns, and bridges [23-25]. Therefore, using LDGC as a sintering additive to improve the sintering performance of Y-TZP is worth of an expectation. Moreover, the addition of glass ceramics with excellent translucency is also a potential way to improve the characterized chalk color of Y-TZP $[8,21,26]$.

In the present study, LDGC fabricated by sol-gel method was introduced into Y-TZP to optimize its mechanical and optical properties. The influence of LDGC addition on the sintering behavior, microstructure, and mechanical properties of Y-TZP had been investigated thoroughly. The optical properties of LDGC added Y-TZP ceramics were also characterized.

\section{Materials and methods}

\section{1 Material fabrication}

Tetraethyl orthosilicate (TEOS; AR, Shanghai Lingfeng Chemical Reagent Co., Ltd., China) and triethyl phosphate (TEP; AR, Sinopharm Chemical Reagent Co., Ltd., China) were honored as precursors of $\mathrm{Si}$ and $\mathrm{P}$, respectively. The molar ratio of the glass components was designed according to $66.3 \mathrm{SiO}_{2}-27 \mathrm{Li}_{2} \mathrm{O}-2.0 \mathrm{Al}_{2} \mathrm{O}_{3}-$ $1.8 \mathrm{~K}_{2} \mathrm{O}-1.7 \mathrm{ZrO}_{2}-1.2 \mathrm{P}_{2} \mathrm{O}_{5}$ system. First, nitric acid (2 $\mathrm{mol} / \mathrm{L}$ ) was added into deionized water to adjust $\mathrm{pH}$ value to 3 , and then TEOS and TEP were added successively. The mixture was stirred under a rotation speed of $300 \mathrm{rpm}$ at room temperature $\left(\sim 25^{\circ} \mathrm{C}\right)$ until a complete hydrolysis was achieved. Meanwhile, lithium nitrate $\left(\mathrm{LiNO}_{3} ; \mathrm{AR}\right.$, Aladdin Industrial Corporation, China), zirconium nitrate pentahydrate $\left(\mathrm{Zr}\left(\mathrm{NO}_{3}\right)_{4} \cdot 5 \mathrm{H}_{2} \mathrm{O}\right.$; AR, Nine-Dinn Chemistry (Shanghai) Co., Ltd., China), potassium nitrate $\left(\mathrm{KNO}_{3}\right.$; $\mathrm{AR}$, Sinopharm Chemical Reagent Co., Ltd., China), and aluminum nitrate nonahydrate $\left(\mathrm{Al}\left(\mathrm{NO}_{3}\right)_{3} \cdot 9 \mathrm{H}_{2} \mathrm{O}\right.$; AR, Sinopharm Chemical Reagent Co., Ltd., China) were sequentially added into deionized water according to the designed proportions, and mechanically stirred until dissolved completely. Second, the obtained aqueous solution was slowly added into the hydrolyzed solution prepared in the first step. The mixed solution was stirred for $24 \mathrm{~h}$, and then held at $60{ }^{\circ} \mathrm{C}$ for $72 \mathrm{~h}$ to form a gel. After that, the gel was dried at $120{ }^{\circ} \mathrm{C}$ for $48 \mathrm{~h}$. The dried gel was heat-treated at $600{ }^{\circ} \mathrm{C}$ for $1 \mathrm{~h}$ with a heating rate of $3{ }^{\circ} \mathrm{C} / \mathrm{min}$, and then calcined at $850{ }^{\circ} \mathrm{C}$ for $2 \mathrm{~h}$ in air atmosphere with a heating rate of $2{ }^{\circ} \mathrm{C} / \mathrm{min}$. Finally, the obtained glass ceramic powders were ground and screened with a 200-mesh sieve for the subsequent experiments.

Y-TZP with $0 \mathrm{wt} \%, 1 \mathrm{wt} \%, 3 \mathrm{wt} \%$, and $5 \mathrm{wt} \%$ of LDGC were prepared in this study, with sample codes of 100Z, 99Z1LD, 97Z3LD, and 95Z5LD, respectively. Y-TZP powders (TZ-3YBE, Tosoh Co., Japan) and pre-prepared LDGC powders were mixed by ball milling in ethanol for $3 \mathrm{~h}$. After ball milling, the mixed powders were dried and screened through 200-mesh sieve, and then compacted into rectangular 
blocks with a dimension of $30 \mathrm{~mm} \times 40 \mathrm{~mm} \times 6 \mathrm{~mm}$, followed by a cold isostatic pressing at $250 \mathrm{MPa}$. Finally, the compacts were sintered at $900-1100{ }^{\circ} \mathrm{C}$ for $2 \mathrm{~h}$ in air atmosphere with a heating rate of $5{ }^{\circ} \mathrm{C} / \mathrm{min}$.

\section{2 Characterizations}

Density of the samples was measured by the Archimedes method with distilled water as the medium. The differential scanning calorimetry (TG/DSC) analysis was conducted by a simultaneous TG/DSC apparatus (STA409 PC, Netzsch, Germany) with a heating rate of $10{ }^{\circ} \mathrm{C} / \mathrm{min}$ under nitrogen atmosphere $(50 \mathrm{~mL} / \mathrm{min})$. The morphology and chemical analyses of the samples were studied by scanning electron microscope (SEM; S-4800N, Hitachi, Japan) and energy-dispersive X-ray spectroscope (EDS; Magellan 400, FEI, USA) after being polished and thermally etched at $1000{ }^{\circ} \mathrm{C}$ for $30 \mathrm{~min}$. The grain size was measured from the SEM micrographs using Nano Measurer software according to the linear interception method. The number of measured grains is about 200. More detailed microstructural features were investigated by transmission electron microscope (TEM; JEM- 2100F, JEOL, Japan). The phase analysis was conducted by X-ray diffractometer (XRD; D/MAX$\mathrm{RBX}$, Rigaku, Osaka, Japan) with $\mathrm{Cu} \mathrm{K} \alpha$ radiation $(\lambda=$ $0.15418 \mathrm{~nm}$ ). Each group of the samples was tested for 3 times. The fraction of the monoclinic phase in $\mathrm{ZrO}_{2}$, $X_{\mathrm{m}}$, was calculated by using the Gravie and Nicholson method [27]:

$$
X_{\mathrm{m}}=\frac{I_{\mathrm{m}(\overline{1} 11)}+I_{\mathrm{m}(111)}}{I_{\mathrm{m}(\overline{1} 11)}+I_{\mathrm{m}(111)}+I_{\mathrm{t}(101)}}
$$

where $I_{\mathrm{t}}$ and $I_{\mathrm{m}}$ represent the integrated intensity (area under the peaks) of the tetragonal (101) and monoclinic (111) and (111) peaks, respectively. The monoclinic volume fraction, $V_{\mathrm{m}}$, is then calculated by the method proposed by Toraya [28]:

$$
V_{\mathrm{m}}=\frac{1.311 X_{\mathrm{m}}}{1+0.311 X_{\mathrm{m}}}
$$

The theoretical densities of the composites can be calculated with the rule-of-mixtures:

$$
\rho_{\mathrm{t}}=\frac{\rho_{\mathrm{l}} \rho_{\mathrm{z}}}{\left(1-x_{1}\right) \rho_{\mathrm{l}}+x_{1} \rho_{\mathrm{z}}}
$$

where $\rho_{\mathrm{t}}$ is the theoretical density of the composite ceramic, $\rho_{1}$ and $\rho_{\mathrm{z}}$ are the theoretical densities of LDGC $\left(2.5 \mathrm{~g} / \mathrm{cm}^{3}\right)$ and Y-TZP $\left(6.10 \mathrm{~g} / \mathrm{cm}^{3}\right)$ [29], respectively, and $x_{1}$ is the weight percentage of the
LDGC additive in the composite ceramic.

\section{3 Mechanical properties}

Both flexural strength and elastic modulus were tested on a universal testing machine (Instron 5566, Instron Co., USA), and measured by the three-point bending method with a loading rate of $0.5 \mathrm{~mm} / \mathrm{min}$ and a support span of $20 \mathrm{~mm}$. The samples were cut and polished into rectangular bars with the size of $3 \mathrm{~mm} \times$ $4 \mathrm{~mm} \times 26 \mathrm{~mm}$. Six bars were tested for each group. The flexural strength was calculated by

$$
\sigma_{\mathrm{f}}=\frac{3 P l}{2 b h^{2}}
$$

where $\sigma_{\mathrm{f}}$ is the flexural strength, $P$ is the breaking load, $l$ is the length of the support span, and $b$ and $h$ are the width and thickness of the bar, respectively.

The fracture toughness was determined by singleedge-notched beam method with a loading rate of $0.05 \mathrm{~mm} / \mathrm{min}$ and a sample span of $20 \mathrm{~mm}$. This test was also carried out on a universal test instrument (Instron 5566, Instron Co., USA). The fracture toughness was calculated by

$$
\begin{aligned}
& K_{\mathrm{IC}}=\frac{3 P l}{b w^{3 / 2}} \times \\
& \frac{1.99 \alpha^{1 / 2}-\alpha^{3 / 2}(1-\alpha)\left(2.15-3.93 \alpha+2.70 \alpha^{2}\right)}{2(1+2 \alpha)(1-\alpha)^{3 / 2}} \\
& \alpha=\frac{a}{w}
\end{aligned}
$$

where $K_{\mathrm{IC}}$ is the fracture toughness, $P$ is the load, $l$ is the span length, $a$ is the depth of the notch, and $w$ and $b$ are the width and thickness of the bar, respectively.

The Vickers hardness was determined by a Vickers indentation hardness tester (TUKON-2100B, Instron Co., USA). For each sample, 5 indentations with a load of $1 \mathrm{~kg}$ were measured on finely polished surface for $10 \mathrm{~s}$.

\section{Results and discussion}

\section{1 Phase characterization}

The fabricated LDGC powder was studied by means of SEM, XRD, and DSC techniques. Figure 1 shows the SEM micrograph, XRD pattern, and DSC profile of the as-prepared powder. The powder, showing particle aggregation in the SEM micrograph, consists of both amorphous phase and crystallization phase, which is characteristic of glass ceramics, where the diffraction 

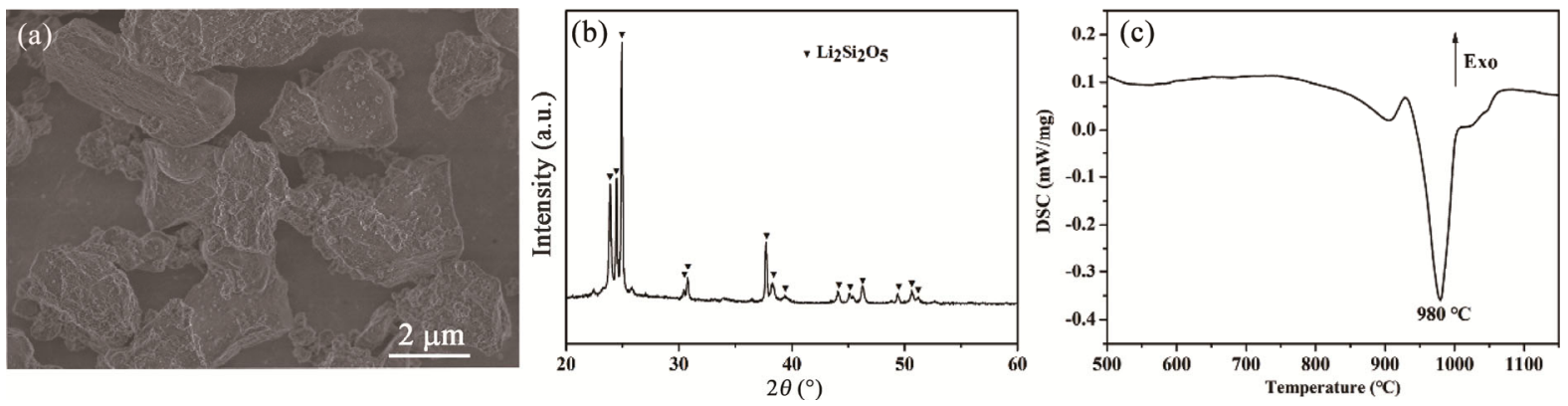

Fig. 1 (a) SEM micrograph, (b) XRD, and (c) DSC profile of the fabricated LDGC powder.

peaks of crystalline can be readily indexed to lithium disilicate (PDF \#72-0102). The DSC profile shows that the melting point of LDGC is $980{ }^{\circ} \mathrm{C}$, which means that LDGC powder will be melted into liquid phase when the sintering temperature is higher than $980{ }^{\circ} \mathrm{C}$.

XRD profiles of the Y-TZP-LDGC samples with different content of LDGC addition sintered at different temperatures are shown in Fig. 2. It is obvious that there coexist the dominant crystalline phase of tetragonal $\mathrm{ZrO}_{2}\left(\mathrm{t}-\mathrm{ZrO}_{2}\right.$; PDF \#80-0965) and the residual phase of monoclinic $\mathrm{ZrO}_{2}\left(\mathrm{~m}-\mathrm{ZrO}_{2}\right.$; PDF \#86-1451). The fraction of $\mathrm{m}-\mathrm{ZrO}_{2}$ is calculated and listed in Table 1. Generally, the $\mathrm{m}-\mathrm{ZrO}_{2}$ fraction increases as a function of the LDGC content. This trend is most evident for the $1100{ }^{\circ} \mathrm{C}$ sintered samples. After sintering at $1100{ }^{\circ} \mathrm{C}$, the $\mathrm{m}-\mathrm{ZrO}_{2}$ fractions are only 14.0 and $13.2 \mathrm{vol} \%$, in the samples $100 \mathrm{Z}$ and 99Z1LD (0 and $1 \mathrm{wt} \%$ of LDGC, respectively). However, when the amount of LDGC addition is $3 \mathrm{wt} \%$, the fraction of $\mathrm{m}-\mathrm{ZrO}_{2}$ increases to $32.7 \mathrm{vol} \%$ sharply. Finally, the $\mathrm{m}-\mathrm{ZrO}{ }_{2}$ fraction reaches at $31.3 \mathrm{vol} \%$ in the sample with $5 \mathrm{wt} \%$ LDGC addition after sintering at $1100{ }^{\circ} \mathrm{C}$.

\section{2 Relative density and mechanical properties}

The relative density (Fig. 3(a)) and mechanical properties, including flexural strength (Fig. 3(b)), elastic modulus (Fig. 3(c)), and hardness (Fig. 3(d)), were also studied with those samples sintered at different temperatures. The results are shown in Fig. 3. The theoretical density of the Y-TZP-LDGC composites is calculated from the theoretical densities reported for tetragonal Y-TZP and LDGC. When the sintering temperature is $900{ }^{\circ} \mathrm{C}$, the relative density of $\mathrm{Y}-\mathrm{TZP}$ is $50.66 \%$. However, with $5 \mathrm{wt} \%$ LDGC addition, the relative density increases linearly to $61.24 \%$, as shown in Fig. 3(a). When sintered at $1000{ }^{\circ} \mathrm{C}$, the relative density of Y-TZP without LDGC is $56.93 \%$. With $3 \mathrm{wt} \%$ LDGC addition, the relative density of the composite rapidly
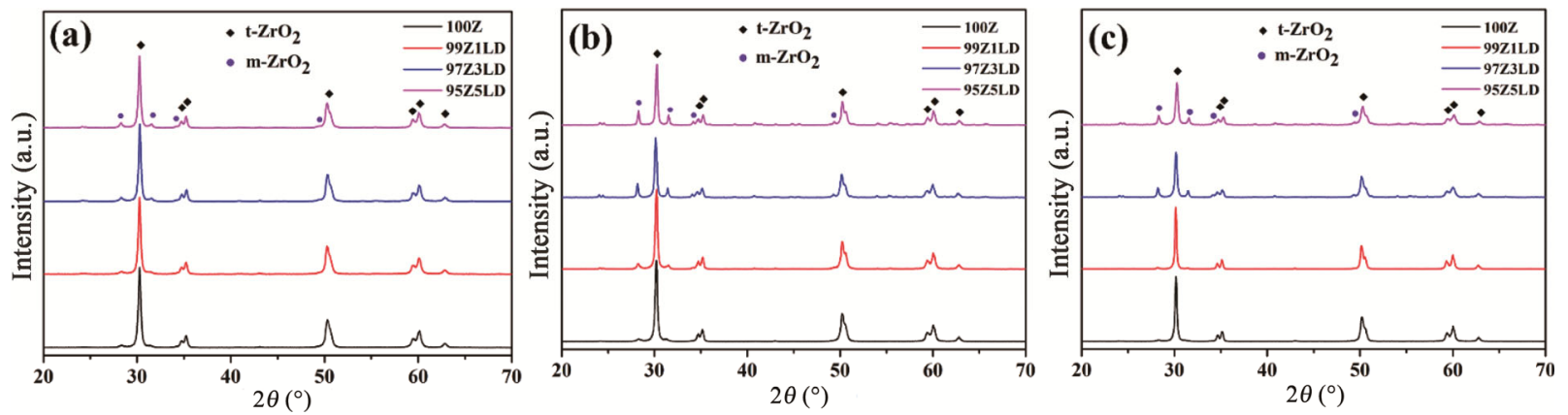

Fig. 2 XRD patterns of the samples with different LDGC content sintered at different temperatures: (a) $900{ }^{\circ} \mathrm{C}$, (b) $1000{ }^{\circ} \mathrm{C}$, and (c) $1100{ }^{\circ} \mathrm{C}$.

Table 1 Volume fraction of monoclinic $\mathrm{ZrO}_{2}$ phase in the sintered Y-TZP-LDGC samples (vol\%)

\begin{tabular}{cccc}
\hline Sample & $900{ }^{\circ} \mathrm{C}$ & $1000{ }^{\circ} \mathrm{C}$ & $1100{ }^{\circ} \mathrm{C}$ \\
\hline $100 Z$ & $13.2 \pm 0.2$ & $11.5 \pm 1.2$ & $14.0 \pm 2.6$ \\
$99 Z 1 L D$ & $14.4 \pm 0.6$ & $18.1 \pm 0.7$ & $13.2 \pm 1.1$ \\
$97 Z 3 L D$ & $16.5 \pm 0.8$ & $29.2 \pm 0.8$ & $32.7 \pm 0.7$ \\
$95 Z 5 L D$ & $19.3 \pm 0.7$ & $28.6 \pm 0.1$ & $31.3 \pm 0.5$ \\
\hline
\end{tabular}



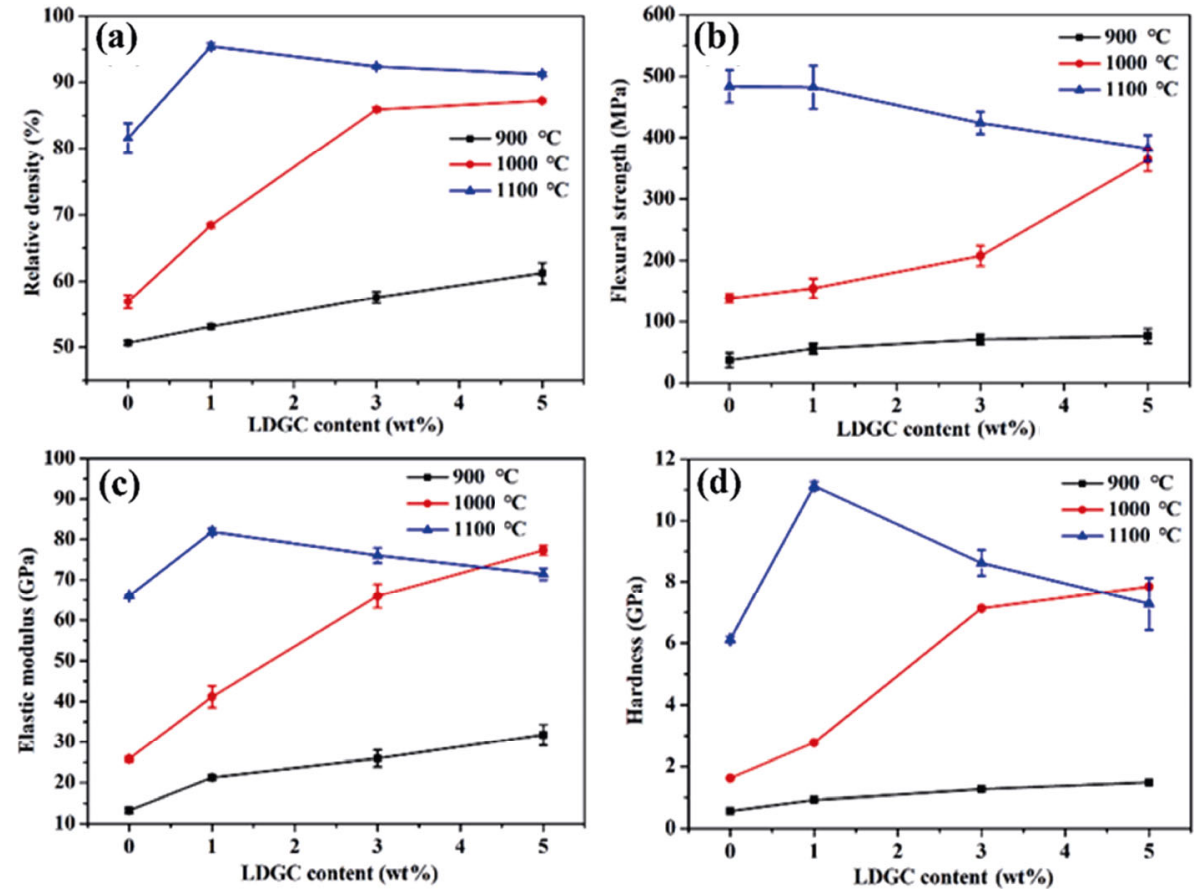

Fig. 3 Relative density and mechanical properties of samples sintered at different temperatures: (a) relative density, (b) flexural strength, (c) elastic modulus, and (d) hardness.

increases up to $85.94 \%$. After sintered at $1100{ }^{\circ} \mathrm{C}$, the relative density of samples greatly increases from $81.58 \%$ to $95.45 \%$ with only $1 \mathrm{wt} \%$ of LDGC addition. However, with a further increase of LDGC addition, the relative density gradually decreases, for example, $91.25 \%$ with $5 \mathrm{wt} \%$ LDGC addition.

The flexural strength increases from 37.0 to $76.6 \mathrm{MPa}$, the elastic modulus from 13.2 to $31.8 \mathrm{GPa}$, and the hardness from 0.6 to $1.5 \mathrm{GPa}$, for the samples sintered at $900{ }^{\circ} \mathrm{C}$ with LDGC addition increasing from 0 to $5 \mathrm{wt} \%$. The flexural strength of samples with $5 \mathrm{wt} \%$ LDGC addition achieves a maximum value of 363.7 $\mathrm{MPa}$, and the elastic modulus and hardness reach to 77.4 and $7.85 \mathrm{GPa}$, respectively, when the sintering temperature reaches at $1000{ }^{\circ} \mathrm{C}$. While the flexural strengths are 483.8 and $482.4 \mathrm{MPa}$, when the LDGC additions are 0 and $1 \mathrm{wt} \%$ at $1100{ }^{\circ} \mathrm{C}$, respectively. However, the flexural strength decreases with more of LDGC content. Consistent with flexural strength, the highest elastic modulus and hardness also reach at 81.9 and $11.13 \mathrm{GPa}$, respectively, when the LDGC addition is $1 \mathrm{wt} \%$. When the LDGC content is further increasing, the elastic modulus and hardness gradually decreased. Furthermore, a similar tendency is observed in the fracture toughness at $1100{ }^{\circ} \mathrm{C}$ as shown in Table 2. The sample 99Z1LD, with $1 \mathrm{wt} \%$ LDGC addition, presents the highest fracture toughness of $5.94 \mathrm{MPa} \cdot \mathrm{m}^{1 / 2}$.

The fracture surfaces of samples sintered at $1100{ }^{\circ} \mathrm{C}$ were studied by SEM as shown in Fig. 4. In Fig. 4(a), it could be found that there are pores at the triplejunction among $\mathrm{ZrO}_{2}$ grains. In sample $99 \mathrm{Z1LD}$, the pores among $\mathrm{ZrO}_{2}$ grains disappeared, which means 99Z1LD has a higher relative density than 100Z. In samples $97 Z 3 \mathrm{LD}$ and $95 \mathrm{Z} 5 \mathrm{LD}$, macro pores can be observed on the fracture surfaces. The existence of these pores reduces the relative density and has a negative effect on the mechanical properties of the samples.

It is noted that the addition of LDGC contributes to the densification of Y-TZP. The melt-out effect of added LDGC at grain boundaries can facilitate the atom diffusion and promote the densification of samples through liquid sintering. In addition, the increment of temperature can reduce the viscosity of glass phase, which can also promote the atom diffusion and thus

Table 2 Fracture toughness of the samples sintered at $1100{ }^{\circ} \mathrm{C}$

\begin{tabular}{ccccc}
\hline Sample & $100 \mathrm{Z}$ & $99 \mathrm{Z} 1 \mathrm{LD}$ & $97 \mathrm{~L}$ LD & 95Z5LD \\
\hline Fracture toughness $\left(\mathrm{MPa} \cdot \mathrm{m}^{1 / 2}\right)$ & $4.98 \pm 0.32$ & $5.94 \pm 0.67$ & $3.91 \pm 0.36$ & $3.70 \pm 0.10$ \\
\hline
\end{tabular}




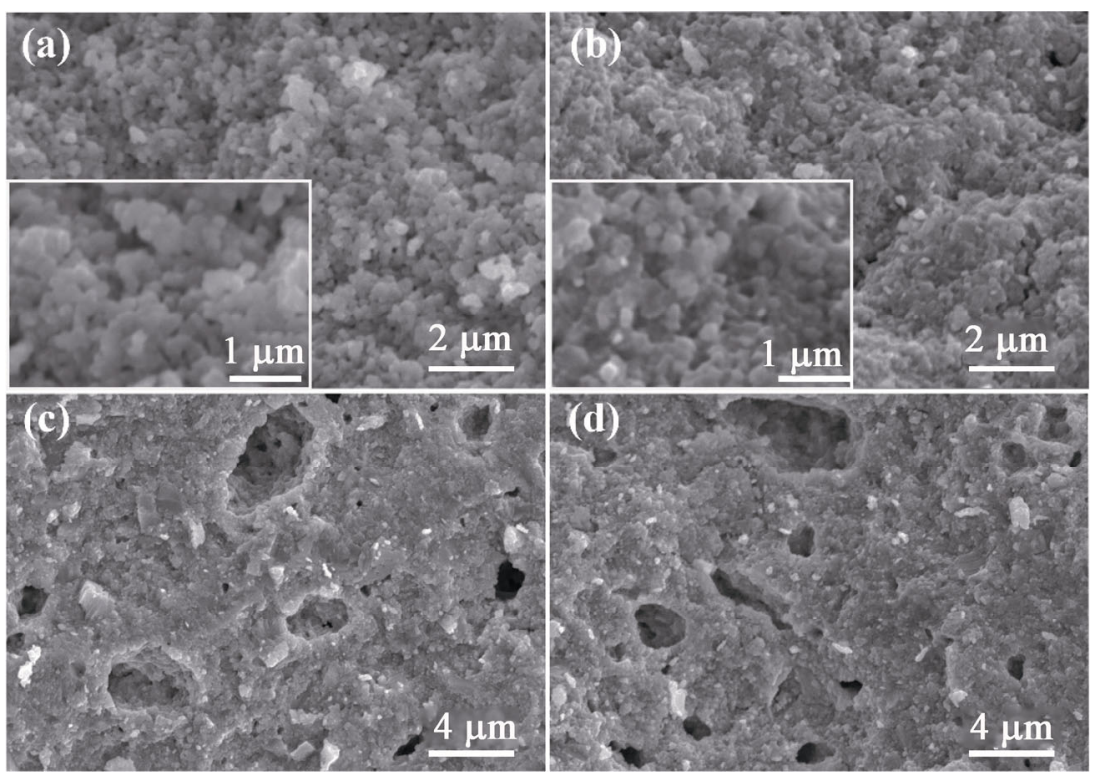

Fig. 4 SEM micrographs of the fracture surfaces of samples sintered at $1100{ }^{\circ} \mathrm{C}$ : (a) 100Z, (b) $99 \mathrm{Z} 1 \mathrm{LD}$, (c) 97Z3LD, and (d) 95Z5LD. The insets show the morphologies at a higher magnification.

facilitate the densification. Therefore, with the increment of LDGC addition and sintering temperature, the relative density of the samples gradually increased. However, when the LDGC addition is more than $3 \mathrm{wt} \%$, the relative density of the samples sintered at $1100{ }^{\circ} \mathrm{C}$ will be decreased. This is induced by the pores within the ceramics (Figs. 4(c) and 4(d)) and the volumetric expansion caused by the $\mathrm{t}-\mathrm{m}$ transformation of $\mathrm{ZrO}_{2}$ grains $[18,30]$.

When the sintering temperatures are 900 and $1000{ }^{\circ} \mathrm{C}$, the relative density of Y-TZP-LDGC samples increases with the increment of LDGC content, and the flexural strength, elastic modulus, and hardness of the samples increase accordingly. After sintering at $1100{ }^{\circ} \mathrm{C}$, the sample with $1 \mathrm{wt} \%$ LDGC addition has the highest values of relative density, elastic modulus, hardness, and fracture toughness at the same time. The above results show that the flexural strength, elastic modulus, and hardness of Y-TZP-LDGC samples follow the same trend and strongly correlate with the variation of relative density, which indicate that the density is a dominate factor for the mechanical properties of Y-TZP-LDGC samples. It is well-known that the lower density of the ceramic indicates more internal pore defects inside (Fig. 4). The pore defects can cause the stress concentration and reduce the cross-sectional area of the material, which is unfavorable for the mechanical properties [11,12]. In addition, the volume expansion caused by $\mathrm{t}-\mathrm{m}$ transformation may result in pores and micro-cracking, and thus the increasing
$\mathrm{m}-\mathrm{ZrO}_{2}$ content has adverse effects on the mechanical properties. Moreover, the excessive intergranular glass phase may negatively affect the mechanical properties of Y-TZP, since the mechanical properties of LDGC are lower than that of $\mathrm{Y}-\mathrm{TZP}$. Therefore, after sintering at $1100{ }^{\circ} \mathrm{C}$, although the density of $97 Z 3 \mathrm{LD}$ and $95 \mathrm{Z} 5 \mathrm{LD}$ is higher than that of $100 \mathrm{Z}$, the flexural strength of them is lower than that of $100 Z$ [15,31].

For zirconia-based materials, stress-induced $\mathrm{t}-\mathrm{m}$ transformation is the primary toughening-reinforcing mechanism. Therefore, the content of $\mathrm{t}-\mathrm{ZrO}_{2}$ plays an important role in the fracture toughness of Y-TZPLDGC samples. In the present work, the density of samples is increased with the addition of LDGC, but the content of $\mathrm{t}-\mathrm{ZrO}_{2}$ will be reduced. For the samples sintered at $1100{ }^{\circ} \mathrm{C}$, the relative density of 99Z1LD is higher than that of $100 \mathrm{Z}$, while its $\mathrm{m}-\mathrm{ZrO}_{2}$ content is close to that of $100 \mathrm{Z}$, and thus the fracture toughness of 99Z1LD is higher than that of 100Z. Although the relative density both of $97 Z 3 \mathrm{LD}$ and $95 \mathrm{Z} 5 \mathrm{LD}$ is higher than that of $100 \mathrm{Z}$, the fracture toughness of them is lower than that of $100 \mathrm{Z}$, which may be caused by the higher $\mathrm{m}-\mathrm{ZrO}_{2}$ content.

\section{3 Microstructural characterization}

Figure 5 shows the SEM micrographs of the original surfaces of samples sintered at $1100{ }^{\circ} \mathrm{C}$. In Fig. 5(a), the sample $100 \mathrm{Z}$ has a uniform grain size and some pores can be observed on its surface (indicated by yellow open circles). With $1 \mathrm{wt} \%$ LDGC addition, pores 


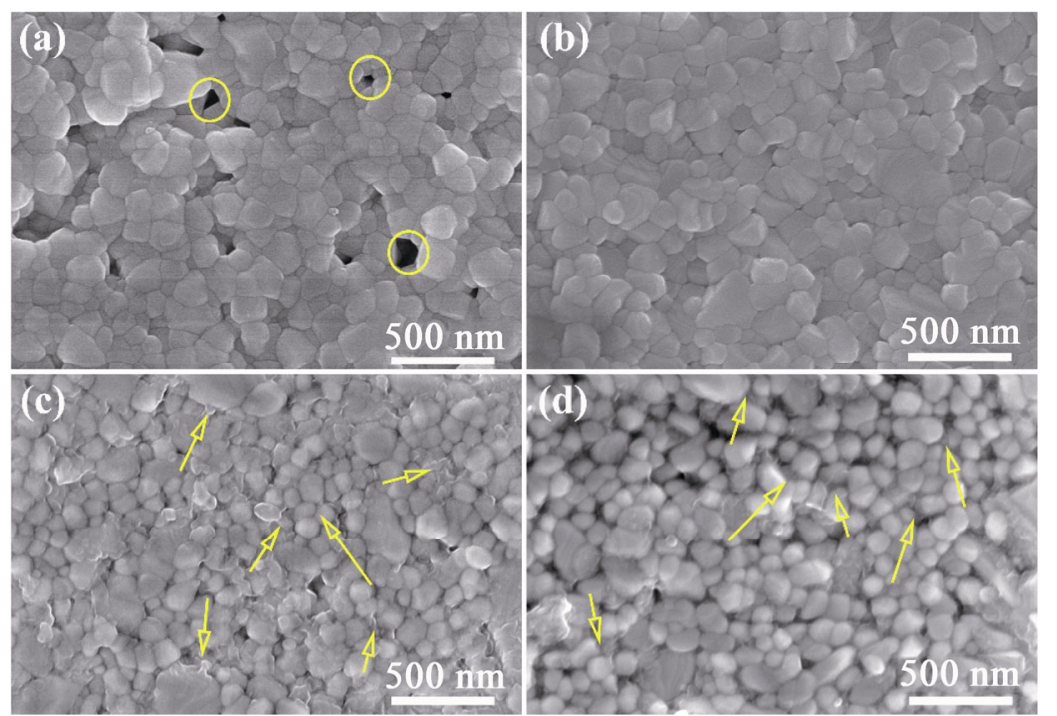

Fig. 5 SEM micrographs of the original surfaces of samples sintered at $1100{ }^{\circ} \mathrm{C}$ : (a) $100 \mathrm{Z}$, (b) $99 \mathrm{Z} 1 \mathrm{LD}$, (c) $97 \mathrm{Z} 3 \mathrm{LD}$, and (d) 95Z5LD. Yellow open circles indicate the pores, and arrows indicate the glass phase.

disappear on the sample surface. When the LDGC addition increases to $3 \mathrm{wt} \%$, a thin glass phase appears at the grain boundaries (by the yellow arrow). As the LDGC addition further increases to $5 \mathrm{wt} \%$, zirconia grains are gradually wrapped by the glass phase, and the thickness of the glass phase at the grain boundary is increased obviously. These results indicate that the LDGC gradually melts and fills the gaps among the $\mathrm{ZrO}_{2}$ grains during the sintering process.

Figure 6 shows SEM micrographs of the polished and thermal etched surfaces of Y-TZP-LDGC samples sintered at $1100{ }^{\circ} \mathrm{C}$. It is clear in Fig. 6(a) that the size of $\mathrm{ZrO}_{2}$ grains is uniform, and there are some intergranular pores in the sample. When $1 \mathrm{wt} \%$ LDGC is added, the intergranular pores disappear, without obvious changes in $\mathrm{ZrO}_{2}$ grain size (Fig. 6(b)). When the LDGC addition is more than $3 \mathrm{wt} \%$, it is remarkable that there shows a bimodal size distribution of $\mathrm{ZrO}_{2}$ grains (Figs. 6(c) and 6(d)); smaller ones are at nano scales (about $100 \mathrm{~nm}$ ), while the larger ones are around $1-4 \mu \mathrm{m}$ as indicated by white circles. Besides, the average diameter of both larger and smaller $\mathrm{ZrO}_{2}$ grains increases gradually with the increasing content of LDGC addition. The shape of smaller $\mathrm{ZrO}_{2}$ grains turns accordingly from polygon into roundness. Table 3 summarizes the average grain size of the samples
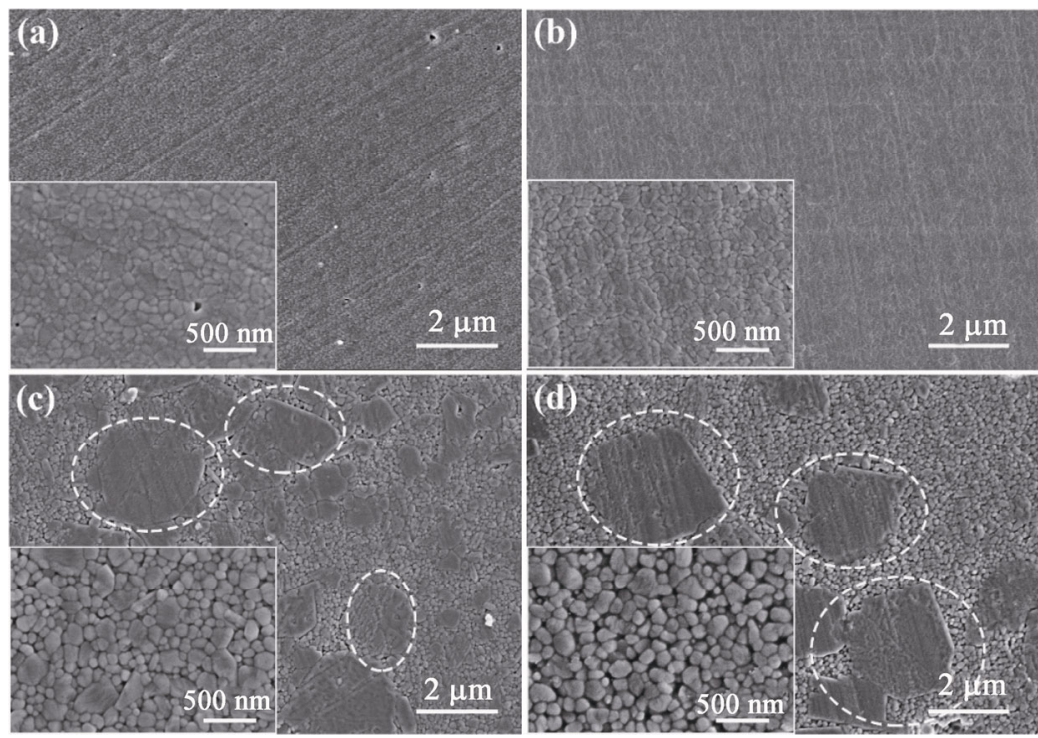

Fig. 6 SEM micrographs of the samples sintered at $1100{ }^{\circ} \mathrm{C}$ : (a) 100Z, (b) 99Z1LD, (c) 97Z3LD, and (d) 95Z5LD. The insets show the morphologies at a higher magnification. White circles indicate the larger grains. 
Table 3 Average grain size of the samples sintered at $1100{ }^{\circ} \mathrm{C}$

\begin{tabular}{ccccc}
\hline Sample & $100 Z$ & $99 Z 1 \mathrm{LD}$ & 97Z3LD & 95Z5LD \\
\hline Average grain size $(\mathrm{nm})$ & $90 \pm 33$ & $107 \pm 39$ & $112 \pm 43$ & $120 \pm 40$ \\
\hline
\end{tabular}

sintered at $1100{ }^{\circ} \mathrm{C}$.

According to liquid phase sintering theory, liquid phase can wet the solid particles, with resulting in capillary pressure in the space between particles, which can promote the densification by rearranging the particles to denser packing and increasing the mass transfer rate through dissolution-reprecipitation mechanism [13,3133]. Therefore, the intergranular pores eliminate in sample 99Z1LD and the relative density of Y-TZP increases with a small amount of LDGC addition. Furthermore, the increased mass transfer rate is conducive to grain growth. Thus, the average grain size of samples is increased as shown in Table 3.

In fact, the LDGC additive mostly distributes at grain boundaries during sintering process. Therefore, the thickness of glass phase grain boundary increases with more addition of LDGC. This thick glass phase grain boundary would hinder the mutual contacts between grains and subsequently increase the diffusion path of grain boundary, resulting in limited mass transfer and low grain-growth rate. Therefore, when LDGC addition is more than $1 \mathrm{wt} \%$, further increase in LDGC content leads to a decrease in relative density. Additionally, the similar result is also observed by Tekeli in $\mathrm{SiO}_{2} / 8 \mathrm{YSCZ}$ (8 mol\% yttria-stabilized cubic zirconia) composites, in which the overdose $\mathrm{SiO}_{2}$ addition has been proved to retard the densification of $8 Y S C Z$ by hindering the grain growth $[34,35]$.

The detailed microstructure on micron and nano scale was analyzed by TEM imaging, electron diffraction as well as chemical analysis. Figure 7 gives the TEM bright field micrographs of 99Z1LD and 97Z3LD samples sintered at $1100{ }^{\circ} \mathrm{C}$. It can be concluded that the grain size of 99Z1LD sample is uniform and the phase of marked grain is demonstrated to be tetragonal $\mathrm{ZrO}_{2}$ (Figs. 7(a) and 7(b)). However, two types of $\mathrm{ZrO}_{2}$ grains with different sizes are present in sample 97Z3LD (Figs. 7(c) and 7(d)), which is consistent with the SEM results (Fig. 6(c)). Furthermore, the selected area electron diffraction (SAED) patterns have confirmed that the larger $\mathrm{ZrO}_{2}$ grains are the monoclinic phase, while smaller ones are cubic (Figs. 7(c)-7(f)).

Elemental mapping results on polished surface of the $1100{ }^{\circ} \mathrm{C}$ sintered samples are shown in Fig. 8. Si distribution reveals the existence of LDGC addition. At this magnification, element distribution of $\mathrm{Zr}, \mathrm{Y}$, and $\mathrm{Si}$ looks homogeneous in the sample of 99Z1LD. However, for 97Z3LD and 95Z5LD samples, it is obvious that the distribution of all the elements is non-uniform, and larger size grains lacking of $\mathrm{Y}$ and $\mathrm{Si}$ elements (white dashed ellipse in Figs. 8(b) and 8(c)) are observed, which further confirm the formation of larger-size $\mathrm{ZrO}_{2}$. Elemental analysis was also performed to fully understand the distribution of glass addition at a higher magnification in TEM. The $\mathrm{Si}$ distribution in Fig. 8(d) indicates that the glass addition is mainly distributed along $\mathrm{ZrO}_{2}$ grain boundaries. Meanwhile, the linear variation of element content in
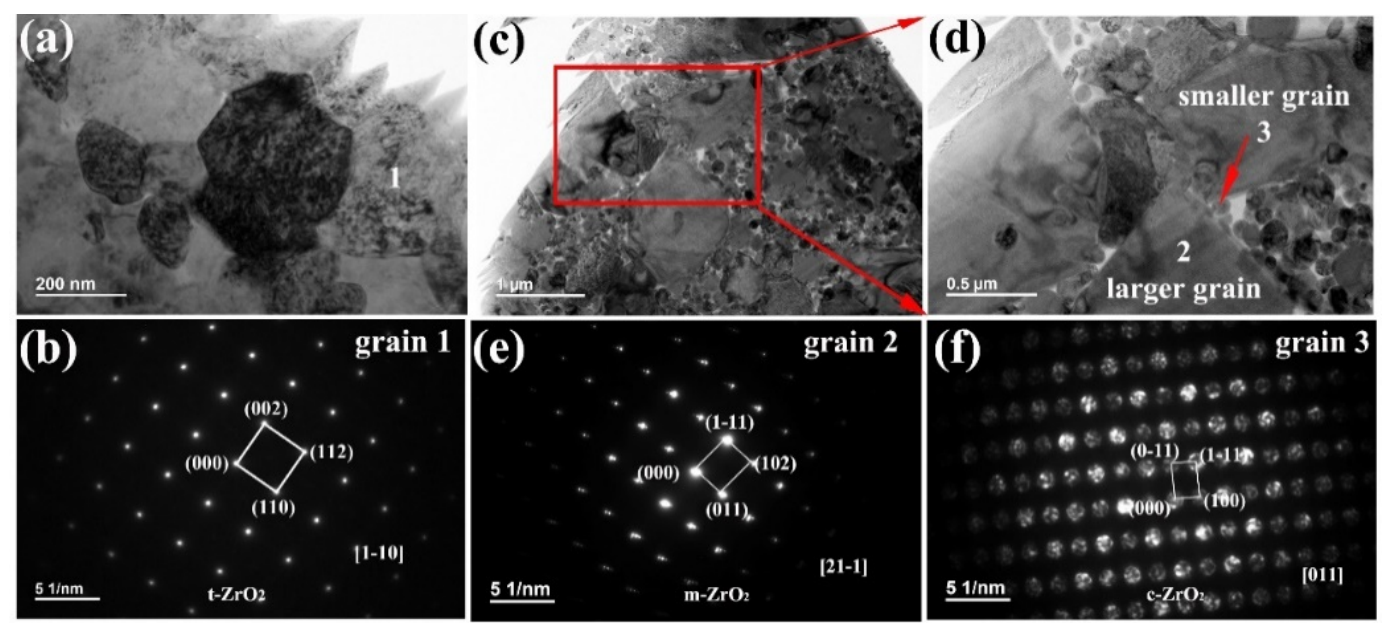

Fig. 7 TEM images of (a) 99Z1LD and (c, d) 97Z3LD sintered at $1100{ }^{\circ} \mathrm{C}$; (b, e, f) SAED patterns of the marked grains with numbers. 

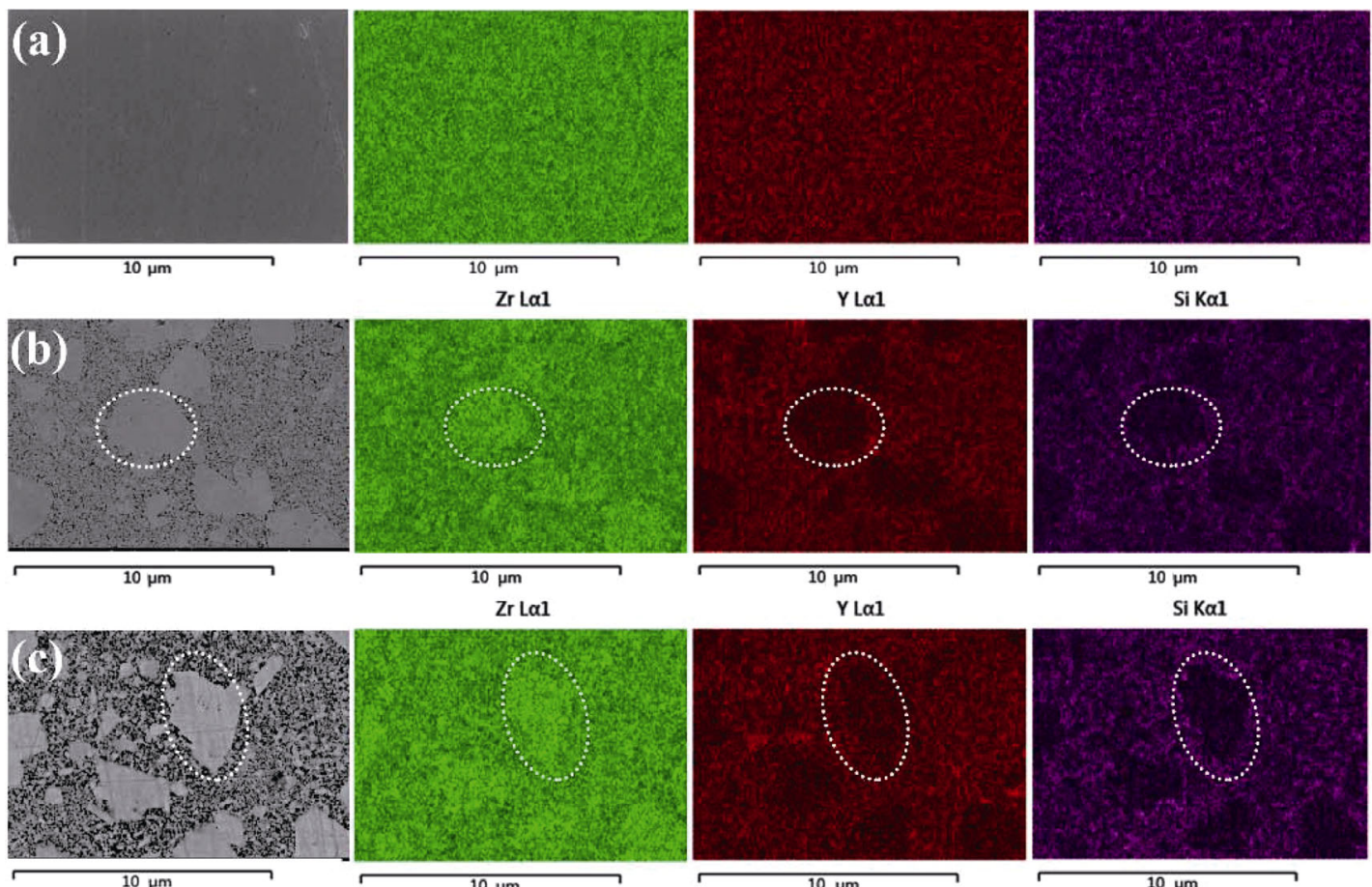

Y L $\alpha 1$
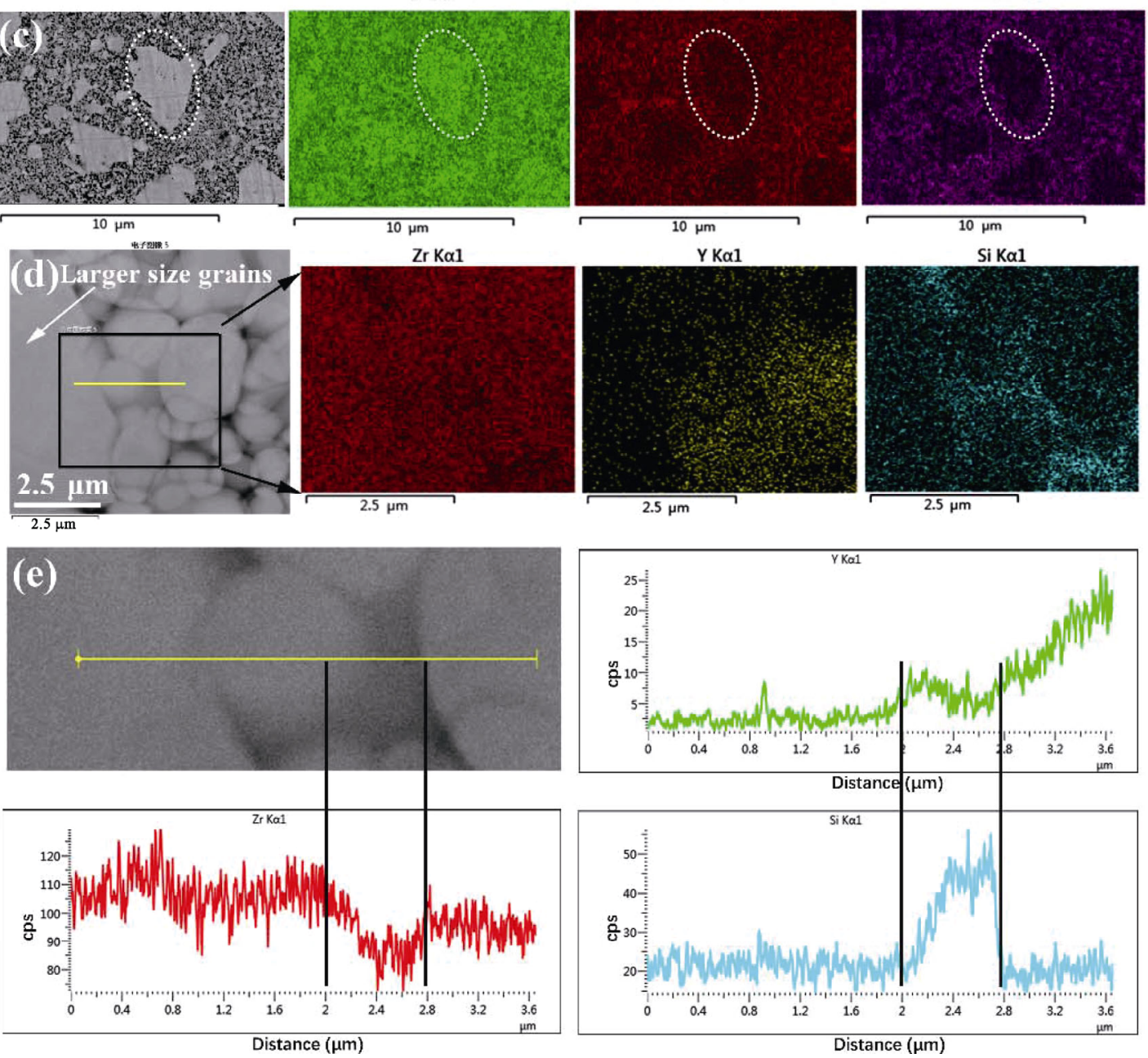

Fig. 8 SEM elemental mappings of the polished surfaces of (a) 99Z1LD, (b) 97Z3LD, and (c) 95ZZ5LD sintered at $1100{ }^{\circ} \mathrm{C}$; (d) TEM elemental mappings and (e) line scan of 97Z3LD sintered at $1100{ }^{\circ} \mathrm{C}$.

Fig. 8(e) shows that the glass addition at the grain boundary riches in yttrium. Therefore, it can be concluded that the $\mathrm{Y}$ element may diffuse from the larger-size $\mathrm{ZrO}_{2}$ into intergranular glass. The consequence is that the lack of $\mathrm{Y}$ in larger-size $\mathrm{ZrO}_{2}$ will directly induce the phase transition from $\mathrm{t}-\mathrm{ZrO}_{2}$ to $\mathrm{m}-\mathrm{ZrO}_{2}$. It is well-known that $\mathrm{Y}_{2} \mathrm{O}_{3}$ is the stabilizing agent of the zirconia. The content and distribution of $\mathrm{Y}$ have a direct influence on the phase form of zirconia [36]. Thus, it is reasonable to suppose that the lack of 
$\mathrm{Y}$ in larger-size $\mathrm{ZrO}_{2}$ will directly induce the phase transition from $\mathrm{t}-\mathrm{ZrO}_{2}$ to $\mathrm{m}-\mathrm{ZrO}_{2}$.

Several studies have shown that the introduction of bio-glass (such as 64S, CaO- $\mathrm{P}_{2} \mathrm{O}_{5}-\mathrm{SiO}_{2}-\mathrm{MgO}$, and $\mathrm{SiO}_{2}-\mathrm{Na}_{2} \mathrm{O}-\mathrm{CaO}-\mathrm{P}_{2} \mathrm{O}_{5}$ ) into $\mathrm{Y}-\mathrm{TZP}$ can induce a $\mathrm{t}-\mathrm{m}$ transformation and lead to an increase in the $\mathrm{m}-\mathrm{ZrO}_{2}$ fraction [30,31,37]. It was explained that this could be caused by the inhomogeneous spreading of liquid phase during the sintering process. In fact, it is difficult to achieve the uniform mixing of precursor powders due to the agglomeration of LDGC powders (Fig. 1(a)). The recrystallization of the inhomogeneous intergranular glass phase and the mismatch in coefficient of thermal expansion between the glass phase and zirconia matrix will cause considerable localized stress and structure changes during cooling process, which may also induce the undesirable phase transition [18].

Although it has been reported for several times that the $\mathrm{m}-\mathrm{ZrO}_{2}$ fraction of $\mathrm{Y}-\mathrm{TZP}$ increases when glasses used as the additive, the phenomenon of $\mathrm{Y}$ segregation has been rarely reported [13,16,18,30,31,35]. Yttrium silicates $(\mathrm{Y}-\mathrm{Si}-\mathrm{O})$, or the $\mathrm{Y}_{2} \mathrm{O}_{3}-\mathrm{SiO}_{2}$ binary system, including $\mathrm{Y}_{2} \mathrm{Si}_{2} \mathrm{O}_{7}, \mathrm{Y}_{2} \mathrm{SiO}_{5}$, and $2 \mathrm{Y}_{2} \mathrm{O}_{3} \cdot 3 \mathrm{SiO}_{2}$, have been widely investigated and used as high-temperature structural ceramics [38-40]. $\mathrm{Y}_{2} \mathrm{SiO}_{5}$ can be obtained by calcining $\mathrm{Y}_{2} \mathrm{O}_{3}$ and $\mathrm{SiO}_{2}$ when lithium used as an additive $[38,41]$. In the $\mathrm{Y}_{2} \mathrm{O}_{3}-\mathrm{SiO}_{2}$ binary system, the additive of lithium can lower the reaction temperature of $\mathrm{Y}_{2} \mathrm{O}_{3}-\mathrm{SiO}_{2}$ by eutectic reactions. Apparently, the introduction of lithium is beneficial to the formation of $\mathrm{Li}-\mathrm{Si}-\mathrm{Y}-\mathrm{O}$ liquid phase and can promote the reaction between $\mathrm{Y}_{2} \mathrm{O}_{3}$ and $\mathrm{SiO}_{2}$. In addition, the previous work has shown that several yttrium silicates, including $\mathrm{Y}_{4.67}\left(\mathrm{SiO}_{4}\right)_{3} \mathrm{O}, \mathrm{Y}_{2} \mathrm{SiO}_{5}$, and $\mathrm{Y}_{2} \mathrm{Si}_{2} \mathrm{O}_{7}$, are obtained in the $\mathrm{Y}_{2} \mathrm{O}_{3}-\mathrm{SiO}_{2}$ system with a lithium additive, after a calcination at $1025{ }^{\circ} \mathrm{C}$ [41]. This might be the reason why $\mathrm{Y}$ element diffuses away from $\mathrm{ZrO}_{2}$ grains to the intergranular lithium-containing glass phase.

The $\mathrm{t}-\mathrm{ZrO}_{2}$ fraction depends both on the grain size and $\mathrm{Y}$ content in samples at room temperature. For 3Y-TZP (3 mol\% yttria-stabilized tetragonal zirconia) used in the present work, the critical grain size of $\mathrm{t}-\mathrm{ZrO}_{2}$ is about $1 \mu \mathrm{m}$, which means the grains larger than $1 \mu \mathrm{m}$ would transfer to $\mathrm{m}-\mathrm{ZrO}_{2}$ during the cooling process [10]. This is in good agreement with the TEM results observed in the present work (Figs. 7(d) and 7(e)). Moreover, the $\mathrm{Y}$ segregation in the Y-TZP-LDGC samples should be noted. It is easy to find that there is more $\mathrm{Y}$ in smaller grains, and less in larger grains. Since the zirconia stabilized by higher Y content (about $8 \mathrm{~mol} \%$ ) can be cubic phase at room temperature $[34,42], \mathrm{c}-\mathrm{ZrO}_{2}$ grain is observed in the region of smaller grains with higher $\mathrm{Y}$ concentration (Figs. 7(d) and 7(f)) [34]. Due to the limited total content of $\mathrm{Y}$ in the starting powders, the content of $\mathrm{c}-\mathrm{ZrO}_{2}$ grains is too low to be detected by the XRD analysis.

\section{4 Translucency}

As can be seen from Fig. 9, the significant difference in translucency is identified among the Y-TZP-LDGC samples sintered at $1100{ }^{\circ} \mathrm{C}$. The optical images show that the additive of LDGC has a significant impact on the translucency of the samples. Specifically, the addition of $1 \mathrm{wt} \%$ LDGC can greatly increase the translucency of the sample. However, with a further increase of LDGC, the translucency gradually decreases.

Limited translucency is a major drawback of Y-TZP and directly influences the appearance of dental restorations $[8,43,44]$. The main factor affected the translucency of Y-TZP is the light scattering, mainly at pores, grain boundaries, or second phases. In the present Y-TZP-LDGC system, the addition component LDGC performs an excellent translucency. According to the above results, the additive of LDGC can eliminate the pores in Y-TZP (as shown in Figs. 5 and 6). Therefore, the addition of LDGC improves the translucency of Y-TZP. However, when the addition is more than $1 \mathrm{wt} \%$, the density of samples decreases dramatically, and the translucency will be correspondingly decreased.

\section{Conclusions}

The present work investigates the influence of LDGC addition on the sintering, mechanical, and translucent properties of $\mathrm{Y}-\mathrm{TZP}$ ceramics. The results show that the addition of LDGC can significantly promote the densification of Y-TZP ceramics through liquid phase

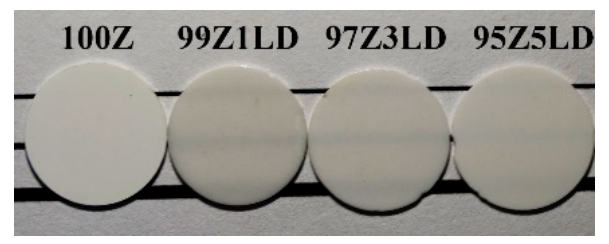

Fig. 9 Optical images of the samples sintered at $1100{ }^{\circ} \mathrm{C}$ (the sample thickness is $0.3 \mathrm{~mm}$ ). 
sintering at relatively lower temperatures. Meanwhile, the addition of LDGC can also cause the yttrium atoms to escape from the zirconia grain lattice to the intergranular glass phase, resulting in an increase of $\mathrm{m}-\mathrm{ZrO}_{2}$ fraction in $\mathrm{Y}-\mathrm{TZP}$ ceramics and a decrease of mechanical properties at the same time. Moreover, the diffusion of $\mathrm{Y}$ atoms from zirconia grain lattice can also result in an abnormal growth of monoclinic grains. When sintered at a relatively low temperature of $1100{ }^{\circ} \mathrm{C}$, Y-TZP added with $1 \mathrm{wt} \%$ LDGC would possess a flexural strength of $482.4 \mathrm{MPa}$ and a fracture toughness of $5.94 \mathrm{MPa} \cdot \mathrm{m}^{1 / 2}$. It also exhibits a better translucency, which is a promising material for all-ceramic dental restorations.

\section{Acknowledgements}

This research was supported by the Shanghai Committee of Science and Technology, China (No. 17441904100).

\section{References}

[1] Raigrodski AJ. Contemporary materials and technologies for all-ceramic fixed partial dentures: A review of the literature. J Prosthet Dent 2004, 92: 557-562.

[2] Guazzato M, Albakry M, Ringer SP, et al. Strength, fracture toughness and microstructure of a selection of all-ceramic materials. Part II. Zirconia-based dental ceramics. Dent Mater 2004, 20: 449-456.

[3] Conejo J, Nueesch R, Vonderheide M, et al. Clinical performance of all-ceramic dental restorations. Curr Oral Heal Rep 2017, 4: 112-123.

[4] Kelly J, Benetti P. Ceramic materials in dentistry: Historical evolution and current practice. Aust Dent J 2011, 56: 84-96.

[5] Elsaka SE, Elnaghy AM. Mechanical properties of zirconia reinforced lithium silicate glass-ceramic. Dent Mater 2016, 32: 908-914.

[6] Gautam C, Joyner J, Gautam A, et al. Zirconia based dental ceramics: Structure, mechanical properties, biocompatibility and applications. Dalton Trans 2016, 45: 19194-19215.

[7] Denry I, Kelly JR. State of the art of zirconia for dental applications. Dent Mater 2008, 24: 299-307.

[8] Zhang F, Inokoshi M, Batuk M, et al. Strength, toughness and aging stability of highly-translucent Y-TZP ceramics for dental restorations. Dent Mater 2016, 32: e327-e337.

[9] Zhu DB, Song YJ, Liang JS, et al. Progress of toughness in dental zirconia ceramics. J Inorg Mater 2018, 33: 363.

[10] Piconi C, Maccauro G. Zirconia as a ceramic biomaterial. Biomaterials 1999, 20: 1-25.

[11] Miranda RBDP, Miranda WG Jr, Lazar DRR Jr, et al. Effect of titania content and biomimetic coating on the mechanical properties of the $\mathrm{Y}-\mathrm{TZP} / \mathrm{TiO}_{2}$ composite. Dent Mater 2018, 34: 238-245.

[12] Garvie RC, Hannink RH, Pascoe RT. Ceramic steel? Nature 1975, 258: 703-704.

[13] Sun YH, Zhang YF, Guo JK. Microstructure and bending strength of $3 \mathrm{Y}-\mathrm{TZP}$ ceramics by liquid-phase sintering with CAS addition. Ceram Int 2003, 29: 229-232.

[14] Hannink RHJ, Kelly PM, Muddle BC. Transformation toughening in zirconia-containing ceramics. J Am Ceram Soc 2000, 83: 461-487.

[15] Ho WF, Hsu HC, Peng YF, et al. Microstructure and mechanical properties of dental 3Y-TZP ceramics by using CaO- $\mathrm{P}_{2} \mathrm{O}_{5}$ glass as additive. Ceram Int 2011, 37: 11691174.

[16] Soubelet CG, Albano MP, Conconi MS. Sintering, microstructure and hardness of $\mathrm{Y}-\mathrm{TZP}-64 \mathrm{~S}$ bioglass ceramics. Ceram Int 2018, 44: 4868-4874.

[17] Soubelet CG, Albano MP. Mechanical properties and aging behaviour of Y-TZP with 64S bioglass additions for dental restorations. Adv Appl Ceram 2019, 118: 329-339.

[18] De Paula Miranda RB, Borges R, Marchi J, et al. Microstructure and flexural strength of the Y:TZP/BG composite. Int J Appl Ceram Technol 2019, 16: 1979-1988.

[19] Bellucci D, Sola A, Cannillo V. Bioactive glass $/ \mathrm{ZrO}_{2}$ composites for orthopaedic applications. Biomed Mater 2013, 9: 015005.

[20] Shi JL, Lu ZL, Guo JK. Model analysis of boundary residual stress and its effect on toughness in thin boundary layered yttria-stabilized tetragonal zirconia polycrystalline ceramics. J Mater Res 2000, 15: 727-732.

[21] Bai Y, Peng L, Zhu QS. The preparation of the lithium disilicate glass-ceramic with high translucency. J Non Cryst Solids 2017, 457: 129-134.

[22] Deng BH, Harris JT, Luo J. Atomic picture of crack propagation in $\mathrm{Li}_{2} \mathrm{O}-2 \mathrm{SiO}_{2}$ glass-ceramics revealed by molecular dynamics simulations. J Am Ceram Soc 2020, 103: 4304-4312.

[23] Daguano JKMB, Milesi MTB, Rodas ACD, et al. In vitro biocompatibility of new bioactive lithia-silica glassceramics. Mater Sci Eng: C 2019, 94: 117-125.

[24] Hoppe A, Güldal NS, Boccaccini AR. A review of the biological response to ionic dissolution products from bioactive glasses and glass-ceramics. Biomaterials 2011, 32: 2757-2774.

[25] Guazzato M, Albakry M, Ringer SP, et al. Strength, fracture toughness and microstructure of a selection of all-ceramic materials. Part I. Pressable and alumina glass-infiltrated ceramics. Dent Mater 2004, 20: 441-448.

[26] Li J, Cui BC, Lin YH, et al. High strength and toughness in chromatic polymer-infiltrated zirconia ceramics. Dent Mater 2016, 32: 1555-1563.

[27] Garvie RC, Nicholson PS. Phase analysis in zirconia systems. J Am Ceram Soc 1972, 55: 303-305.

[28] Toraya H, Yoshimura M, Somiya S. Calibration curve for 
quantitative analysis of the monoclinic-tetragonal $\mathrm{ZrO}_{2}$ system by X-ray diffraction. J Am Ceram Soc 1984, 67: C119-C121.

[29] Swain MV. Unstable cracking (chipping) of veneering porcelain on all-ceramic dental crowns and fixed partial dentures. Acta Biomater 2009, 5: 1668-1677.

[30] Habibe AF, Maeda LD, Souza RC, et al. Effect of bioglass additions on the sintering of Y-TZP bioceramics. Mater Sci Eng: C 2009, 29: 1959-1964.

[31] Santos C, Souza RC, Habibe AF, et al. Mechanical properties of Y-TPZ ceramics obtained by liquid phase sintering using bioglass as additive. Mater Sci Eng: A 2008, 478: 257-263.

[32] German RM, Suri P, Park SJ. Review: liquid phase sintering. J Mater Sci 2009, 44: 1-39.

[33] Liu JW, Zhou XB, Tatarko $\mathrm{P}$, et al. Fabrication, microstructure, and properties of $\mathrm{SiC} / \mathrm{Al}_{4} \mathrm{SiC}_{4}$ multiphase ceramics via an in situ formed liquid phase sintering. $J A d v$ Ceram 2020, 9: 193-203.

[34] Tekeli S, Gürü M, Sağlam OE. Densification and graingrowth behavior of various amounts of $\mathrm{SiO}_{2}$ doped $8 \mathrm{YSCZ} / \mathrm{SiO}_{2}$ composites. Mater Manuf Process 2007, 22: 710-714.

[35] Bicalho LA, Baptista CARP, Souza RC, et al. Fatigue and subcritical crack growth in $\mathrm{ZrO}_{2}$-bioglass ceramics. Ceram Int 2013, 39: 2405-2414.

[36] Drożdż E, Wyrwa J, Schneider K, et al. Electrical properties of silica-doped $3 \mathrm{~mol} \%$ yttria-stabilized tetragonal zirconia. J Mater Sci 2017, 52: 674-685.

[37] Stábile MF, Soubelet CG, Albano MP, et al. Effect of 64S bioglass addition on sintering kinetic, flexural strength and osteoblast cell response of yttria-partially stabilized zirconia ceramics. Int J Appl Ceram Technol 2019, 16: 517-530.

[38] Sun ZQ, Li MS, Zhou YC. Recent progress on synthesis, multi-scale structure, and properties of $\mathrm{Y}-\mathrm{Si}-\mathrm{O}$ oxides. Int Mater Rev 2014, 59: 357-383.
[39] Haritha AH, Rao RR. Sol-gel synthesis and phase evolution studies of yttrium silicates. Ceram Int 2019, 45: 2495724964.

[40] Ma QS, Cai LH. Fabrication and oxidation resistance of mullite/yttrium silicate multilayer coatings on $\mathrm{C} / \mathrm{SiC}$ composites. J Adv Ceram 2017, 6: 360-367.

[41] Sun ZQ, Zhou YC, Li MS. Effect of $\mathrm{LiYO}_{2}$ on the synthesis and pressureless sintering of $\mathrm{Y}_{2} \mathrm{SiO}_{5}$. J Mater Res 2008, 23: 732-736.

[42] Shi JL, Ruan ML, Yen TS. Crystallite growth in yttriadoped superfine zirconia powders and their compacts: A comparison between Y-TZP and YSZ. Ceram Int 1996, 22: 137-142.

[43] Camposilvan E, Leone R, Gremillard L, et al. Aging resistance, mechanical properties and translucency of different yttria-stabilized zirconia ceramics for monolithic dental crown applications. Dent Mater 2018, 34: 879-890.

[44] Zhang F, van Meerbeek B, Vleugels J. Importance of tetragonal phase in high-translucent partially stabilized zirconia for dental restorations. Dent Mater 2020, 36: 491-500.

Open Access This article is licensed under a Creative Commons Attribution 4.0 International License, which permits use, sharing, adaptation, distribution and reproduction in any medium or format, as long as you give appropriate credit to the original author(s) and the source, provide a link to the Creative Commons licence, and indicate if changes were made.

The images or other third party material in this article are included in the article's Creative Commons licence, unless indicated otherwise in a credit line to the material. If material is not included in the article's Creative Commons licence and your intended use is not permitted by statutory regulation or exceeds the permitted use, you will need to obtain permission directly from the copyright holder.

To view a copy of this licence, visit http://creativecommons. org/licenses/by/4.0/. 